\title{
All's Well That Ends Well? On the Importance of How Returns Are Achieved
}

\author{
Grosshans, Daniel ; Zeisberger, Stefan
}

\begin{abstract}
We demonstrate that investor satisfaction and investment behavior are influenced substantially by the price path by which the final investor return is achieved. In a series of experiments, we analyze various different price paths. Investors are most satisfied if their assets first fall in value and then recover, and they are least satisfied with the opposite pattern, independent of whether the final return is positive or negative. Price paths systematically influence risk preferences, return beliefs, and ultimately trading decisions. Our results enable a much more holistic perspective on a wide range of topics in finance, such as the disposition effect, risk-taking behavior after previous gains and losses, and behavioral asset pricing.
\end{abstract}

DOI: https://doi.org/10.1016/j.jbankfin.2017.09.021

Posted at the Zurich Open Repository and Archive, University of Zurich ZORA URL: https://doi.org/10.5167/uzh-166069

Journal Article

Accepted Version

Originally published at:

Grosshans, Daniel; Zeisberger, Stefan (2018). All's Well That Ends Well? On the Importance of How Returns Are Achieved. Journal of Banking and Finance, 87:397-410.

DOI: https://doi.org/10.1016/j.jbankfin.2017.09.021 


\title{
All's Well That Ends Well? On the Importance of How Returns are Achieved*
}

\author{
Daniel Grosshans ${ }^{\dagger}$ and Stefan Zeisberger ${ }^{\ddagger}$
}

First Version: July 16, 2014

This Version: August 4, 2017

\begin{abstract}
We demonstrate that investor satisfaction and investment behavior are influenced substantially by the price path by which the final investor return is achieved. In a series of experiments, we analyze various different price paths. Investors are most satisfied if their assets first fall in value and then recover, and they are least satisfied with the opposite pattern, independent of whether the final return is positive or negative. Price paths systematically influence risk preferences, return beliefs, and ultimately trading decisions. Our results enable a much more holistic perspective on a wide range of topics in finance, such as the disposition effect, risk-taking behavior after previous gains and losses, and behavioral asset pricing.
\end{abstract}

Keywords: investor satisfaction, reference points, risk tolerance, investor behavior, experimental finance

JEL classification: D14, D81, G11

*The authors thank Charlotte Borsboom, Thorsten Hens, Jürgen Huber, Danling Jiang, Michael Kirchler, Thomas Langer, Amos Nadler, Alexandra Niessen-Ruenzi, Michaela Pagel, Hersh Shefrin, Martin Weber as well as participants of the following university research seminars and conferences for helpful comments and suggestions: Stockholm Business School, University of Frankfurt, University of Innsbruck, University of Hannover, Newcastle University, Stony Brook University, University of Münster, University of Zurich, Research in Behavioral Finance Conference Amsterdam 2016, Behavioural Finance Working Group Conference 2016, IFABS China Meeting 2015, Experimental Finance Conference 2015, 25th SPUDM conference 2015.

${ }^{\dagger}$ Department of Banking and Finance, University of Zurich

${ }_{\ddagger}^{\ddagger}$ Corresponding author; Institute for Management Research, Radboud University, Nijmegen, and Department of Banking and Finance, University of Zurich, e-mail: s.zeisberger@fm.ru.nl 


\section{Introduction}

Imagine your favorite soccer team is down at half-time, but recovers in the second half, and the match ends with a draw. You would probably be very satisfied with your team turning around the match and getting away with a draw. Now consider the same match with your favorite team being up at half-time, and the final score is again a draw. In this case, you would probably be quite dissatisfied with that very same final score.

In this paper we analyze if, as for sports fans, investor satisfaction and investment behavior depend on the price path with which (final) returns are achieved. We are particularly interested in "non-straight" price paths as in the sports example above, as opposed to simple upward or downward trends. So far, the relevant finance literature has mostly analyzed these simple "straight" paths (simple upward or downward trends), if at all, and the impact on forecasts, trading behavior and mutual fund flows. Some relevant behavioral finance research focused mostly on responses to previous gains and losses, which neglects the price path. Hence this literature has assumed that investor behavior is based on experienced final returns only. Against this background, we investigate if investors care about how a final return was achieved in terms of satisfaction, and we study whether and how price paths affect investment decisions. We thereby analyze risk and return expectations as well as dynamics in risk tolerance that might explain the psychological importance of how returns are achieved.

To answer this research question we conduct a series of experiments in which we carefully use different paths of stock prices that produce equal final returns over a fixed investment period. Analyzing return and risk forecasts, we are able to study the effect of past price patterns on expectations. Eliciting reference points, such as the price that produces zero utility, allows us to explore the impact of past price paths on risk tolerance. We combine all these measures on an individual investor level to explain investors' trading decisions.

Our results demonstrate that investor satisfaction indeed heavily depends on the price path of the assets, especially for "non-straight" price paths that we are most interested in. For both overall gains and losses, investors are most satisfied if their assets first fall in value and then recover, and they are least satisfied with the opposite pattern. We exclude alternative factors such as skewness as drivers for our findings. Furthermore, we find that price paths affect return expectations in the form of short-term momentum beliefs. Risk expectations depend on price paths, too, as our participants use past volatility as a proxy

for future volatility estimates. Concerning reference points, we conclude that they are more sensitive to price increases than to price decreases, i.e., reference points are shifted close to the current price of a stock if this price is above the purchase price while the reference 
point remains close to the purchase price when current prices are below the purchase price. Investors' trading decisions are the result of a combination of our different measures and cannot be explained by single factors such as reference points.

Our analysis finds its roots in the psychology literature which indicates that the order of a sequence of outcomes can be important. Generally, the order of qualitative information can influence judgments or decisions, as found in different domains, e.g., in medical decision making (Bergus et al., 1998) or consumer research (Haugtvedt and Wegener, 1994). Closer related, Alexander and Ang (1998) empirically find order effects in earnings announcements on the asset price development of U.S. equity. Loewenstein and Prelec (1993) present more general evidence that individuals prefer sequences of events to start with the least pleasurable ones and end with the most pleasurable ones. Similarly, Read and Powell (2002) show that for a stream of payments, people chose the lower-valued of a pair of cash flow sequences if that stream comes with an increasing trend. However, Guyse et al. (2002) compare sequence preferences in the environmental domain with those in health and money, and they find that these preferences can be domain-specific and are less stable than possibly assumed. In a more related context to ours using monetary gambles, Heyman et al. (2004) show that satisfaction with the outcome of one gamble seems to be affected by the outcome of previous gambles. In summary, apart from Heyman et al. (2004), the mentioned literature has in common that it is concerned with preferences over hypothetical future non-risky sequences before these are realized. With financial investments this is different. Investors can be more or less satisfied about a realized past sequence of returns, but usually investors face unknown future sequences of returns when deciding about their investment. Hence, while taking the idea of order effects, we study the impact of past return sequences (price paths) on satisfaction and and decisions for future risky investments.

As indicated above, previous literature in finance has mostly analyzed single aspects of how past returns affect future investor satisfaction, behavior or asset prices, focusing on either belief formation or preference shifts. Regarding beliefs De Bondt (1993) and Greenwood and Shleifer (2014), for example, show that investors show a belief in shortterm trend continuation. Sirri and Tufano (1998) and Choi et al. (2010) provide evidence that past fund performance leads to higher fund inflows by investors. Hendricks et al. (1993) and Ippolito (1992) analyze that this belief and behavior might be justified for mutual funds as they observe one-year return persistence. With regard to trading behavior, Da et al. (2015) indicate that a series of gradual changes has a lower impact on prices (trend continuation) than stronger price changes, explained by limited attention. Related, Grinblatt and Moskowitz (2004) and Watkins (2003) find that return consistency in stocks, defined as the frequency of negative/positive returns over a time period, positively affects future 
risk-adjusted returns. These results are interesting for our research question as they provide evidence that the composition of a final return can matter. With regard to the influence of past performance on preferences, previous literature has analyzed how past (final) returns affect trading behavior, mainly in the disposition effect (Shefrin and Statman, 1985; Weber and Camerer, 1998; Odean, 1999; Grinblatt and Keloharju, 2001).

We start with studying investor satisfaction as we expect effects to be particularly pronounced here, potentially affecting trading behavior. Recently, finance literature has started to pay more attention to investor satisfaction. For example, using an investor sample of a UK bank, Merkle et al. (2015) find relative performance, i.e. comparisons to a benchmark, to be an important driver for investor satisfaction. Merkle (2017) shows that investors feel less dissatisfied with financial losses than they anticipated, a behavior he calls loss aversion illusion. Ultimately, satisfaction is what investors are interested in.

Against this background, our paper extends previous literature in several important ways. We analyze order effects in a clean investment frame and apply a wide range of different asset price paths and combine them with final returns in both the gain and the loss domain. Importantly, not only do we study how satisfaction depends on the past price path, but we also relate this for the same investor to an analysis on shifts in beliefs (return and risk predictions) and preferences (reference points). This unique combination of our measures satisfaction, return and risk forecasts and reference points provides valuable insights into the psychological factors driving investment decisions. We conclude that single factors might be insufficient to explain how investors achieve at their trading decision, and importantly the price path plays a crucial role for all of the elements. Numerous control experiments support the internal and external validity of our findings and make alternative explanations very unlikely to drive our results.

Our results call for an incorporation of these findings into finance theories and models. One application is the disposition effect, for which most of the literature has assumed that the purchase price of an asset serves as the reference point. With our analysis we can distinguish between cases in which the disposition effect occurs and does not occur or even reverts. Other implications concern explaining forecast patterns or changes in investors' risk preferences. We conclude that price paths seem to be an important factor to explain investor trading behavior. 


\section{Experimental Design}

\subsection{Stock Price Paths}

The underlying idea of our experiment is to test whether a stock's price path between two points in time affects investor satisfaction and investment behavior. The centerpiece of our experiments is the existence of three characteristic stock price developments, which we will henceforth call "down-up," "straight," and "up-down." As the names suggest, "down-up" represents a stock price development for which the price first decreases but recovers afterwards. Analogously, for "up-down," the stock price first rises and then decreases. "Straight" represents a quasi-monotonic stock price development, i.e., there are no pronounced peaks or troughs. Each of these three types of paths is combined with an overall return of $+10 \%$ ("winner") and one of $-10 \%$ ("loser"), so that there are six stock price paths overall, as depicted in Figure 1. 1

We simulated price paths with 2520 ticks plotted on a time axes going back one year from today, which is meant to correspond to 10 ticks in a year with 252 trading days in order to make the price paths look as realistic as possible. We intentionally chose a one-year time frame since the one year price chart is a widely used standard format, particularly used as the default chart on many internet platforms. Furthermore, this corresponds with insights from the literature on myopic loss aversion (Benartzi and Thaler, 1995). The authors present evidence that investors use an internal evaluation horizon of 12 months even if the actual investment period is longer.

Our minimum and maximum prices of the non-straight price paths are at either $-30 \%$ or $+30 \%$, measured from the purchase price. To control for timing, the peak and trough prices of all stocks occur at the same point of time, namely after seven months. This guarantees that the slopes of the price paths before and after the turning point are not too different from each other. We deliberately refrained from using a turning point after exactly one-half of the observation period, since this might have looked too artificial. Also, we standardized our charts concerning the scaling of the axes. In particular, the scaling of the vertical axis was harmonized among all graphs, so that the ratio of max and min prices on the vertical axis is the same for all charts. This also holds true for the highest and lowest realized prices, which implies that the rectangular area between the max and min realized prices in the

\footnotetext{
${ }^{1}$ Generally, we characterize an up-down price path by a peak price considerably above the purchase price (in our case 30pp, but could be lower), and for which prices generally stay above the purchase price, but below the peak price. For down-up this is analogous. Our testing of smaller peaks/troughs and various different shapes of the exact paths make us confident that the found consequences are robust to these relatively generally described characteristics.
} 

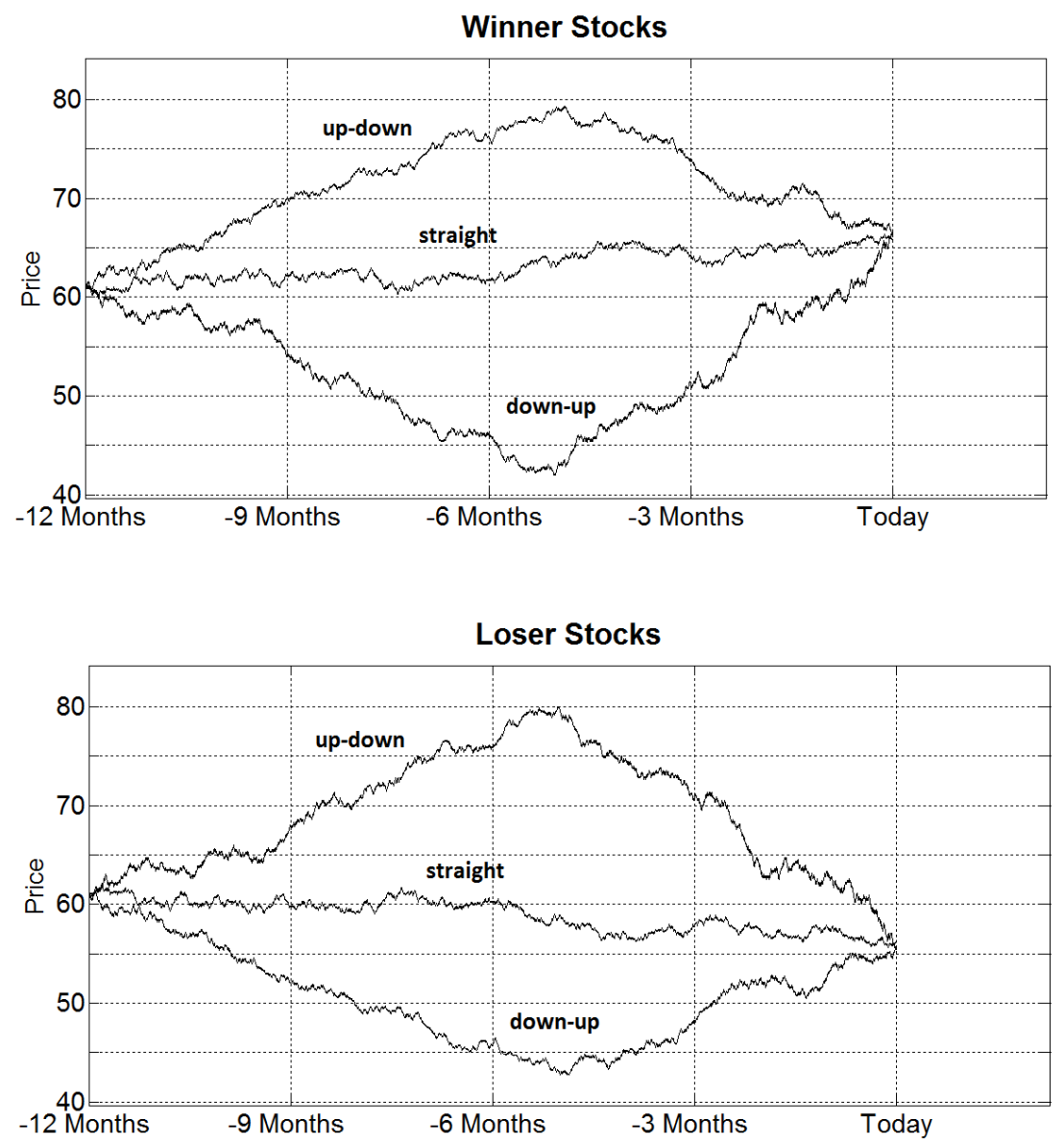

Figure 1. Price paths for winner (upper graph) and loser stocks (lower graph) as used in the experiment. In the experiment different starting prices were used for different stocks. All winner stocks yield a final return of $+10 \%$, all loser stocks, $-10 \%$.

charts was identical. This implies, however, that the latter standardization was not possible for the "straight" path, but some compromise cannot be avoided. To be consistent with the previous literature and to avoid unintended effects for our forecasting task, this area was set to $40 \%$ or $53 \%$ for the down-up and up-down paths (Lawrence and O'Connor, 1992; Glaser et al., 2007). Given our counterbalanced experimental design with gains and losses and the two non-straight price paths (as well as robustness checks reported later) we can almost certainly rule out that scaling effects drive our results. Also, the number of horizontal lines was kept between six and nine for all charts. 


\subsection{Experimental Procedure}

In the beginning of the experiment, participants were instructed to imagine that they had bought stocks one year ago and that they are now observing how their investment performed over that year (see Appendix A). In the baseline experiment, participants were presented with a random subset of three out of the six stocks. ${ }^{2}$ To eliminate order effects, we randomized the order of the presented stocks for each participant. We ran a control experiments, reported later, in which participants were only shown single stocks, thus we can fully rule out any possibility for group or order effects.

The initial price of each stock was randomized and could take values between 53 and 82 monetary units. This range is similar to the average real prices of blue chip stocks traded in major indices such as the DJIA or SMI. ${ }^{3}$ The randomization of prices was used to arrange that the three presented stocks be independent from each other.

For each stock they were presented with, we asked participants about their satisfaction with its performance on a 9-point Likert scale from "very unsatisfied" to "very satisfied." We further asked them to state how likely they would hold or sell this stock on a 4-point Likert scale from "very likely hold" to "very likely sell." Additionally, participants had to state their "minimum selling price" (or selling price at which they would neither be happy nor unhappy selling the stock) as a measure for the reference point (which is relevant to asses the impact of preferences). Last, we asked for a point estimate of the stock's price after one more year as well as for bounds of a 90-percent confidence interval of their prediction.

For the experiments in which there were multiple independent stock prices for the same participant, once being presented with the next stock, participants could not return to revise their answers concerning a previously seen stock. At the end of the experiment, participants answered socio-demographic and further questions, such as their investment experience (see Appendix A).

\subsection{Participants and Incentives}

We conducted a series of online experiments between spring 2014 and spring 2016. In total, we recruited more than 2,000 participants from Amazon Mechanical Turk (MTurk), an online platform that allows so-called "workers" to perform tasks like answering academic surveys in exchange for money. MTurk is nowadays a widely used and accepted recruiting

\footnotetext{
${ }^{2}$ The composition of stocks in each of the two subsets was pre-determined and was either down-up winner, straight loser and up-down winner in one group and down-up loser, straight winner and up-down loser.

${ }^{3}$ Rubaltelli et al. (2005) demonstrated magnitude effects of absolute values, i.e., higher absolute values yield systematically different results concerning satisfaction. We tested whether our results depend on the absolute price using pairwise comparisons between prices, but we found no systematic effects.
} 
platform tool for economic experiments. The behavior of its participants has been found to be very similar to that of the student populations typically used in lab settings (Goodman et al., 2013). Still, we did not want to rely on this finding, and hence we ran control sessions with 128 students from advanced finance courses at the University of Zurich. All sessions were conducted online using survey software. To facilitate participation, the experiment only required a standard internet browser and connection.

In our baseline experiment, we analyze answers from 144 participants on Mturk. ${ }^{4}$ In Appendix C, Table 12, we report a descriptive summary over all experiments discussed in this paper which includes the number of participants as well as a short description of each experiment. In the baseline experiment, it took participants 4:34 minutes to complete the survey so that the time spent for each presented stock scenario was approx. 45 seconds on average - and the remaining time was allocated to answer the final questionnaire and reading the short instructions. The mean age of the participants was 31 years, and $27 \%$ of the participants were female. We paid participants a compensation of $\$ 0.50$ in our online experiment, which corresponds to an hourly wage of approx. $\$ 7$ for the average time it took participants to finish the experiment. Payments were handled automatically by the Amazon Payments system.

\section{Results}

\subsection{Satisfaction}

We start with the results of the baseline experiment $(n=144$, Experiment 1, Table 12) in which each participant was presented with a subset of three stocks, presented in random order. We test whether differences in self-stated satisfaction with the respective investment can be explained by the final return. Figure 2 presents evidence that the price path affects investment satisfaction substantially. We define the "satisfaction gap" as the largest difference in satisfaction between paths for the same final return. This gap amounts to 1.81 in the gain and 2.71 in the loss domain. To test the importance of the price path formally, we compare linear models for investment satisfaction with and without controlling for the price path. The estimation results are reported in Table 1.

As expected from Figure 2, we find that investment satisfaction is significantly altered

\footnotetext{
${ }^{4}$ We excluded data from participants who took less than 2:00 minutes to complete the questionnaire to ensure that sufficient time was spent on the decisions (22 of a total of 166 participants) so that we analyze answers from 144 participants. For consistency, we apply similar restrictions for all control experiments but do not report details each time to streamline the paper. These restrictions do not qualitatively change any of our results.
} 
by the price path. Investors appear to be most satisfied with price paths which have decreasing prices that afterwards (partially) recover, i.e. the down-up path. They are least satisfied with the performance of the stocks whose prices first went up and fell afterwards up-down. We furthermore take into account that self-reported satisfaction could be affected by expectations about the future development of our stocks. ReturnExpectation controls for each participants expected future return in a stock. Looking at column (I) in Table 1 we find indeed that the price path alters satisfaction significantly. Furthermore, we see that satisfaction is to be understood as satisfaction with the past performance of the stock since individual return expectations cannot add significantly to explaining differences in satisfaction. Interestingly, we observe that participants that overall stated more optimistic forecasts also stated higher satisfaction, as can be seen from column (II) in Table 1 where we do not control for subject fixed effects. Overall, we find that while the return difference of 20 percentage points leads to a 3 point difference in average satisfaction, price paths influence satisfaction by 2 points, controlling for other factors. Hence, price paths substantially affect satisfaction comparable to considerable differences in achieved final returns, in our particular setting about 13pp.

\subsection{Checking for Alternative Explanations}

\section{a) Financial Literacy}

To exclude that our results are driven by alternative factors, we ran several robustness checks. First, to check if our results are not driven by those participants with low financial literacy, we ran a robustness check and repeated our analysis, but only analyzed the answers of participants with at least an average level of self-stated financial literacy (3 to 5 on a 5 point Likert scale) which resulted in the exclusion of $41 \%$ of the participants. We do not find any meaningful difference from our baseline results for the restricted set of participants: orders and differences between paths remain nearly unchanged.

However, since self-reported financial literacy scores might not be a good proxy for true financial literacy (Gaudecker, 2015), we repeated the experiment, this time with 58 advanced finance students (28\% female) from the University of Zurich in Switzerland (Experiment 2, Table 12). ${ }^{5}$ We sent participants an e-mail invitation with a link to the study to conduct the survey at a place and time of their convenience within a time frame of one week, hence similar to our baseline experiment. The average time to complete the experiment amounted

\footnotetext{
${ }^{5}$ To incentivize participation, we gave students a 10\% chance to win 20 Swiss Francs (approx. 22 USD at the time of the experiment). Participants were explicitly and clearly told that the winning probability was independent of any of their answers during the experiment.
} 


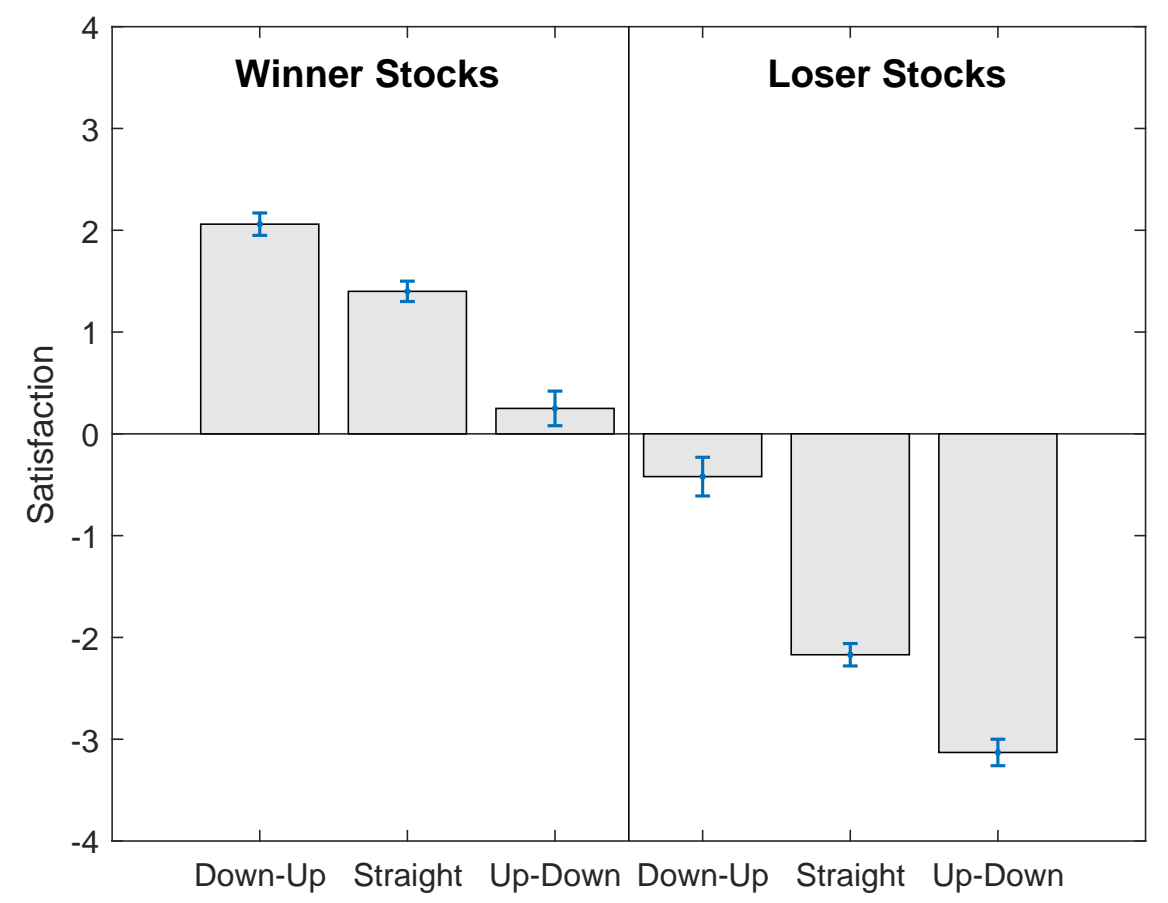

\begin{tabular}{lcccc}
\hline \hline & Down-Up & Straight & Up-Down & Satisfaction Gap \\
\hline Winner Stocks & $+2.06(0.11)$ & $+1.40(0.10)$ & $+0.25(0.17)$ & $1.81^{* * *}$ \\
Loser Stocks & $-0.42(0.19)$ & $-2.17(0.11)$ & $-3.13(0.13)$ & $2.71^{* * *}$ \\
\hline
\end{tabular}

Figure 2. Means of self-reported satisfaction with investment in baseline experiment, reported on a 9-point Likert scale from -4 to $+4,0$ indicating a neutral evaluation. Standard errors are reported in parentheses and depicted by the bars. The satisfaction gap measures the maximum satisfaction difference in one domain (gains or losses). We compute unpaired $t$-statistics to test whether the difference in satisfaction within both domains is different from zero.

to 6:41 minutes and was thus higher than for the MTurk participant pool. This total time left participants with approx. 1:20 minutes for each chart plus some time for reading the short instructions and filling out the questionnaire. As in our baseline experiment, we only presented students with three of the six stocks at one given point in time with the same grouping as in our baseline experiment. However, due to their availability, we presented them with the remaining three stocks a week later. Hence, student subjects were presented with all six stock price developments, but we divided the experiment into two sessions with a time lag of one week to prevent that charts are compared too much. We randomized the two parts and the chart order within each part between the participants.

Even for this more sophisticated subject pool of advanced finance students, all major findings of our baseline experiment can be confirmed. In Table 2 we report the means of sat- 


\begin{tabular}{lcc}
\hline \hline \multicolumn{3}{c}{ Dependent Variable: Satisfaction } \\
& $(\mathrm{I})$ & $(\mathrm{II})$ \\
\hline Constant & $7.084^{* * *}$ & $6.249^{* * *}$ \\
& $(0.941)$ & $(0.160)$ \\
& 0.427 & $1.2162^{* *}$ \\
Return Expectation & $i$ & $(0.520)$ \\
& $(0.621)$ & -0.093 \\
Reference Point & \\
& 0.767 & $(0.465)$ \\
& $(0.663)$ & \\
$\mathbb{1}_{\text {Loser }}$ & $-3.049^{* * *}$ & $-2.975^{* * *}$ \\
& $(0.165)$ & $(0.159)$ \\
$\mathbb{1}_{\text {Down-Up }}$ & $0.926^{* * *}$ & $0.908^{* * *}$ \\
& $(0.196)$ & $(0.199)$ \\
$\mathbb{1}_{\text {Up-Down }}$ & $-1.1434^{* * *}$ & $-1.099^{* * *}$ \\
& $(0.192)$ & $(0.196)$ \\
\hline Subject Fixed Effects? & Yes & No \\
$\mathrm{N}$ & 432 & 432 \\
Adj. $R^{2}$ & 0.550 & 0.525 \\
F Statistic & $4.560^{* * *}$ & $96.100^{* * *}$ \\
\hline \hline
\end{tabular}

Table 1 Satisfaction Regression

This table shows the estimation results of a linear regression model to explain investment satisfaction in our experiment. The dependent variable Satisfaction ${ }_{i}$ ranges on a scale from -4 to +4 . The data is taken from our Baseline Experiment in which each participant was presented with three stocks. Forecast and Reference Point are measured as differences to the final price of the respective stock.

isfaction and test whether the satisfaction gap remains significant. For both overall positive and negative return, satisfaction levels differ considerably. The size of the satisfaction gaps amount to $79 \%$ to $93 \%$ of the ones in our baseline study. Since students in this sample were presented with all six price paths we compute paired $t$-statistics to find that the satisfaction gap is significant at the $1 \%$ level for both winner and loser stocks. The difference between the worst winner and best loser stock is slightly larger than for the baseline experiment. Importantly, overall directions of effects are the same as in the baseline experiment. We conclude that our baseline results are a robust finding that are not limited to investors with possibly low financial literacy.

\section{b) Size of Peaks and Troughs}

To make sure that our results are not driven by the relatively high peak and trough sizes of 


\begin{tabular}{lcccc}
\hline \hline & Down-Up & Straight & Up-Down & Satisfaction Gap \\
\hline Winner Stocks & $+1.92(0.23)$ & $+1.65(0.16)$ & $+0.26(0.24)$ & $1.66^{* * *}$ \\
Loser Stocks & $-0.88(0.21)$ & $-2.22(0.19)$ & $-3.02(0.16)$ & $2.14^{* * *}$ \\
\hline
\end{tabular}

Table 2 Means of self-reported satisfaction with investment for participant pool of advanced finance students, reported on a 9-point Likert scale from -4 to $+4,0$ indicating a neutral evaluation. Students in this sample where presented with all six price paths. Standard errors are reported in parentheses. The satisfaction gap measures the maximum satisfaction difference in one domain (gains or losses). We compute paired $t$-statistics to test whether the difference in satisfaction within both domains is different from zero.

$+/-30 \%$ measured from the purchase price), we conducted a further control experiment with $n=70$ finance students ( $16 \%$ female) from the University of Zurich in which we presented stocks with less extreme price paths (Experiment 3, Table 12), i.e., in scenarios with a peak/trough, prices only go $+/-20 \%$ from the purchase price. Despite these less pronounced peaks and troughs, we find the same pattern in stated satisfaction with the different stocks as in our baseline experiments. As could be expected, satisfaction gaps are slightly smaller for the less salient price paths. The graphs and results are reported in Appendix B. The straight paths are the same as in our baseline experiment.

\section{c) Additional Numerical Information and Single Stock Observation}

Despite all measures we already took to exclude any order or group effects by presenting each participant with three or six stocks overall, we ran a control session, analyzing answers of 423 MTurk participants (31\% female) in which each participant was only presented with one single stock price path (Experiment 4, Table 12). Additionally, typical financial reports include further numerical information about the investment. A usual representation includes the purchase price, the current price and the return. Since in our baseline sessions we refrained from stating numerical information, our results might be biased, and the important return information might have been less salient than in typical bank statements online or offline. Hence, in this robustness check we included numerical information as displayed in Figure 3.

Our results for this robustness check are shown in Table 3. Despite the changes (i.e., presenting only one single return and showing numerical return and price data) they confirm our baseline findings. The satisfaction levels are considerably different for different paths in both the gain and loss domains. The satisfaction gap amounts to 1.73 in the gain and 1.40 in the loss domain, and is thus $70 \%$ the size of the effect we observed in our baseline experiment. Even presenting investors with their return in plain numbers - as is often done in financial reports - seems only to be able to vanish our strong findings to some extent. Given that we conducted an unreported robustness check in which we presented participants 


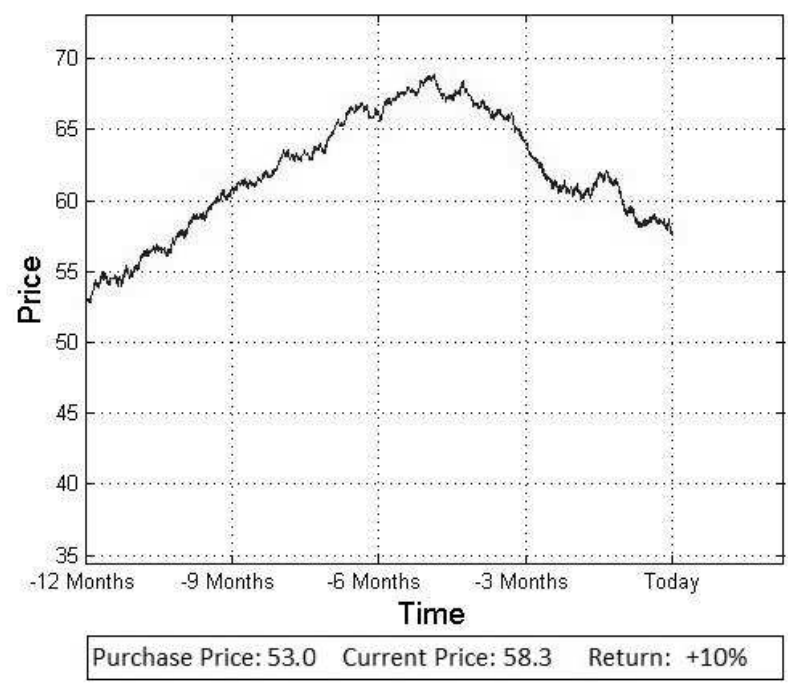

Figure 3. Price paths with additional numerical information as used in control experiment, here for the "up-down" winner stock with a purchase price of 53.

only with single price paths, we can attribute the slightly lower size of the effect to the more salient presentation of the return.

\begin{tabular}{lcccc}
\hline \hline & Down-Up & Straight & Up-Down & Satisfaction Gap \\
\hline Winner Stocks & $+1.95(0.13)$ & $+1.80(0.10)$ & $+0.22(0.23)$ & $1.73^{* * *}$ \\
Loser Stocks & $-1.15(0.16)$ & $-2.07(0.13)$ & $-2.55(0.20)$ & $1.40^{* * *}$ \\
\hline
\end{tabular}

Table 3 Self-reported satisfaction with investment in control experiment with additional numerical information on investment return, reported on a scale from -4 to +4 . Standard errors reported in parentheses. We compute unpaired $t$-statistics to test whether the difference in satisfaction within both domains is different from zero.

\section{d) Timing of Turning Points, Shape of the Price Path, and Other Factors}

Having shown the general relevance of past price developments, we want to make sure that our exact shapes of the price charts do not matter within a category as up-down or down-up. We also aim to understand the impact of certain characteristics of the past prices. We therefore analyze answers of another 500 MTurk participants (39\% female) who were presented with stock price charts that differed with respect to the timing of the turning point (Experiment 5, Table 12). Participants observed turning points after 3 months from the beginning in the "early" charts and after 9 months in the "late" charts. We find that the differences in satisfaction between price paths is robust to the timing of turning points. The 
satisfaction gap between the down-up and up-down price paths is persistent and remains significant.

By comparing different timing of the turning points, we are also able to rule out that our results are caused by preferences over higher orders of the return distribution (skewness in particular) rather than the price path. For each price path down-up or up-down, the return series is once positively skewed and once negatively skewed. We compare the up-down and down-up price paths with the same timing of the turning point. We find that the down-up price path is preferred over the up-down price path regardless whether it has negatively or positively skewed returns. Hence, skewness preferences do not seem to explain our findings. In Table 13 in the Appendix we report the skewness as well as other statistical properties of these price paths' return distribution. In Table 14 we report the stated satisfaction of our participants with the respective price paths.

Generally, we conclude that the exact shape of the price paths (within our definition of up-down and down-up) is of minor importance, and the three characteristic price paths capture the main differences we analyze. ${ }^{6}$

\section{e) Perceived Realism of Price Paths}

As a further robustness check, we ran a control experiment with 564 participants $(46 \%$ female) in which we additionally asked each participant "How realistic do you perceive such a stock price development?" from "very artificial" (1) to "very realistic" (5) (Experiment 6, Table 12). The purpose of this robustness check is to exclude the possibility that different stock price paths are perceived as differently realistic or artificial. The average rating varies only between 3.46 (down-up winner) and 3.88 (straight winner) for the different paths, and we do not find any meaningful or systematic differences. For example, the high-volatility up-down loser has a 3.75 rating while the overall average rating is also 3.75. As an additional robustness check, our results also hold true if we focus our analysis on subjects with only high values $(\geq 3)$ of perceived realism. Hence, our results are generally very unlikely attributed to differences in perceived realism of the price charts we used.

\subsection{Further Explanations and Relating Satisfaction to Experi- enced Utility}

Are our findings of price path dependent satisfaction directly implied by existing concepts of (realized) investor utility? It can be easily shown that mean-variance preferences based on

\footnotetext{
${ }^{6}$ Additionally, in an unreported experiment, we tested price paths with an extended peak or trough that remained for a period of six months. The results are quantitatively very similar to our baseline results.
} 
experienced outcomes cannot explain our satisfaction results. This becomes clear as for the winner stock the down-up path is preferred over the straight up path. However, the down-up path has a higher variance than the straight path, so mean-variance investors would favor the straight price path. For the loser scenario this is difficult to judge as Sharpe ratios based on experienced prices are negative. Nonetheless, down-up and up-down paths have more or less the same variance (down-up winner slightly higher variance than up-down winner, for the loser stocks vice versa), but satisfaction differences are largest between these two cases. As a consequence, mean-variance preferences based on realized returns cannot explain our findings.

Cumulative Prospect Theory (CPT) could be an alternative explanation for our observed results. Arkes et al. (2008) and Thaler and Johnson (1990) indicate that previous outcomes matter for future decisions, explained by shifts in reference points. In order for CPT to potentially explain our results, investors have to gain satisfaction from evaluating different parts of the return sequence separately, otherwise they would only assess the final return. Let us assume investors to split the sequence into two parts, separated by the peak/trough. If an investor does not adapted her reference point but always evaluated in relation the purchase price, price sequences that stay above the purchase price (up-down) would be preferred. However, this is not what we find. Hence, non-adaptation of reference points seems impossible to be able to explain our findings.

If, to the contrary, an investor fully adapted the reference point along with the realized price, this cannot explain our findings either. Note that up-down and down-up sequences have almost the same return components, just in a different order. ${ }^{7}$ This makes a CPT explanation for satisfaction very unlikely. Note that we would have exactly the same return components between up-down and down-up if we had used a neutral final return of $0 \%$. Given the strength of our results we do not find any reason to assume that for neutral final returns our results would be fundamentally different. Hence, any combination of risk or loss preferences (or probability weighting) can also very likely be excluded, as they are applied on the same two return components (just in a different order).

What is needed for CPT to explain our results is that the order in the return sequence matters for the investor - additionally to reference point adaptation - and that the recent part of a sequence is overweighted. This generally favors down-up paths. This is exactly what we hypothesize in our paper and how we motivate our research question, namely that the order of returns matter and that price recoveries are favored. Thus, CPT can be made compatible with our findings only if the order of returns is taken into account and

\footnotetext{
${ }^{7}$ For winner stocks the numbers are (re-ordered): $+30 \%$ and $-20 \%$ for up-down and $+40 \%$ and $-30 \%$ for down-up. For loser stocks: $+30 \%$ and $-40 \%$ for up-down and $+20 \%$ and $-30 \%$ for down-up.
} 
recent components have the higher weight. Our arguments are largely independent of exact specifications of the value and probability weighting functions.

\subsection{Investment Behavior}

Our results on self-stated satisfaction demonstrate a very pronounced price-path dependency. A positive return might be perceived as being more similar to a negative return than to an equally sized positive one, depending on the price path with which this return was achieved. This influence on investor satisfaction is interesting in itself, and, as we reported, has not been investigated yet. Ultimately, investors can be expected to strive for maximizing their satisfaction with their investments. However, at least equally important is the question whether price paths also affect investment behavior.

The formation of an investment decision depends on both expectations (beliefs) and preferences. Traditional finance has mainly focused on the relation between (perceived) expected return and risk, i.e., risk produces negative and expected return positive utility. However, there is still limited knowledge as to how individuals form their risk and return expectations. Furthermore, preferences, i.e., risk tolerance, have been found to be influenced by past performance (see, e.g., Barberis et al. (2001); Cohn et al. (2015)). Yet, there has not been a holistic approach towards understanding the drivers of an investment decision. The symmetric structure of the price paths in our experiments allows us to contribute to filling this gap. Against this background, we will divide the analysis of our findings in two parts. First, we will discuss the role of return and risk expectations, i.e., how price paths influence

predictions for future price changes. Second, we study the impact of past performance on risk preferences by analyzing reference point dynamics.

The following results refer to our baseline experiment (Experiment 1). Despite the many robustness checks, findings for the following results do not differ in any meaningful or significant way from our baseline results.

\section{a) Beliefs: Return Expectations and Risk Expectations}

In this section we discuss the impact of price paths on return expectations. The participants in our baseline experiment were asked to state one-year point estimates of a stock's future price as well as lower and upper bound of $90 \%$ confidence intervals for their estimate. Overall, participants stated realistic expectations about future returns. Derived from the price point estimates, the average expected return was $+3.9 \%$. Taking the arithmetic average of the lower and upper bounds of the forecast intervals, we obtain an implied (under a Normal Gaussian) expected mean return of $1.0 \%$, which shows that our participants on average expected larger downside risks. 


\begin{tabular}{|c|c|c|}
\hline \multicolumn{3}{|c|}{ Dependent Variable: Return Expectation $_{i}$} \\
\hline Constant & $\begin{array}{l}-0.023 \\
(0.095)\end{array}$ & $\begin{array}{l}-0.105 \\
(0.075)\end{array}$ \\
\hline $\mathbb{1}_{\text {Loser }}$ & $\begin{array}{l}-0.023 \\
(0.016)\end{array}$ & $\begin{array}{c}0.016 \\
(0.013)\end{array}$ \\
\hline $\mathbb{1}_{\text {Down-Up }}$ & $\begin{array}{c}0.040 * * \\
(0.022)\end{array}$ & $\begin{array}{c}0.046 * * \\
(0.018)\end{array}$ \\
\hline $\mathbb{1}_{\text {Up-Down }}$ & $\begin{array}{c}-0.063^{* * *} \\
(0.021)\end{array}$ & $\begin{array}{c}-0.045^{* * *} \\
(0.016)\end{array}$ \\
\hline${\text { Forecast Interval } \text { Width }_{i}}$ & $\begin{array}{c}0.171^{* * * *} \\
(0.044)\end{array}$ & $\begin{array}{c}0.255^{* * *} \\
(0.035)\end{array}$ \\
\hline Forecast Skewness $_{i}$ & & $\begin{array}{c}-0.483^{* * *} \\
(0.036)\end{array}$ \\
\hline Subject Fixed Effects? & Yes & Yes \\
\hline $\mathrm{N}$ & 432 & 432 \\
\hline Adj. $R^{2}$ & 0.078 & 0.436 \\
\hline F Statistic & $1.250^{*}$ & $3.250^{* * *}$ \\
\hline
\end{tabular}

Table 4 Return Expectation Regression This table shows the estimation results of a linear model to explain 1-year return forecasts of our participants. Return Expectation ${ }_{i}$ is directly derived from participants price forecasts and measured in percentage points. Forecast Interval Width ${ }_{i}$ reflects participants' $90 \%$ confidence forecast range and is also measured in percentage points. Forecast Skewness $s_{i}=$ $\mid$ Lower Bound - Estimate $\mid$ - |Upper Bound-Estimate $\mid$, i.e. measuring whether the point estimate is closer to the upper or the lower bound of the forecast confidence interval.

To achieve a more detailed view, Table 4 reports estimation results of a regression model explaining return expectations. We observe that price paths alter return expectations significantly. The coefficients indicate that participants exhibit a strong belief in short-term trend continuation. This means in particular, that we do not find evidence for beliefs in prices reverting to the initial purchase price or historical average price. Over a horizon of one year, this does seem reasonable given findings about trend continuation (see, e.g., Jagadeesh and Titman (1993), Hong and Stein (1999), De Bondt (1993) or Greenwood and Shleifer (2014)). Price paths with final upward sloping trends receive more optimistic forecasts than downward sloping price paths. ${ }^{8}$

\footnotetext{
${ }^{8}$ Glaser et al. (2007) report that when asking for price forecasts of a stock, investors particularly expect stocks with downward sloping trend to revert in the opposite direction of this trend while they only found a belief in trend continuation when they were asking for return (as opposed to price) expectations. However,
} 
Another interesting observation is the link between return and risk expectations. As reported in Table 4, there is a positive correlation between return expectations and the width of forecast intervals. Since we cannot clarify causality here, there are two possible interpretations: On the one hand, the positive relation between the interval width and expected return might simply imply that participants assume returns to come at the cost of higher risk. On the other hand, investors might hedge more optimistic forecasts with wider forecast intervals. Further support for this interpretation is reported by De Bondt (1993): He presents evidence that individuals with optimistic return expectations appear to hedge their prediction for the future price distribution by assuming the distribution be left-skewed while individuals with pessimistic return expectations assume the future price distribution to be right-skewed. In column (II) in Table 4 we control for approximated skewness of forecasts by

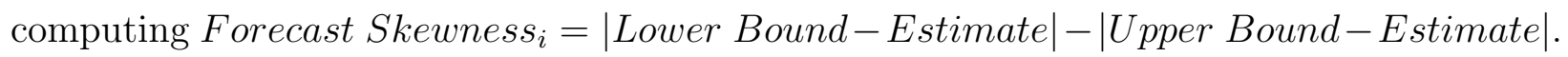
In line with De Bondt (1993), we find a negative relation between the skew of the forecasts and the return (point) estimate.

Our price paths come with different realized volatility. While the price paths of the straight stocks have an overall (annual) volatility of only $8.6 \%$, the most volatile stocks, i.e., the down-up winners and up-down losers have a volatility of $17.0 \%{ }^{9}$. As a consequence, our participants might assign a higher expected risk (implicit volatility, i.e., forecast interval) to a stock with a higher realized risk. From the width of the forecast intervals we see that participants did indeed assign narrower intervals to the straight stocks with the lowest past volatility. This means that participants did find stocks to not be equally risky, and they used past graphical volatility to predict future volatility. In Table 5 we report estimation results for a regression model explaining the width of our participants' forecast intervals. We group price paths by their variance and find that differences in realized volatility are also reflected in expected risk.

Expected risk could have been further influenced by experienced returns. However, this was not the case as can be inferred from the coefficient for the loser indicator in Table 5 which is not significantly different from zero: There appears to be no significant effect of paper returns on risk expectations. This fact is particularly important since it allows us to conduct a more differentiated analysis of investment behavior. It is unlikely that past performance makes investors "blind" to risk. Hence, a relative preference for one of two

we used a 12-month time horizon while those authors based their analysis on 1-month and 6-month forecasts. Even though we asked our participants to report price forecasts, we observe results in line with those reported by Glaser et al. (2007) for the case of asking for return forecasts.

${ }^{9}$ We calculated volatility by aggregating ten ticks to obtain quasi-daily returns and multiply by $\sqrt{252}$ to obtain annual volatility under the assumption of a normal distribution in order to allow comparison with real stocks. 
stocks with equal volatility but different past performances is not likely to have been caused by an inability to understand the risk component.

\begin{tabular}{lc}
\hline \hline Dependent Variable: Forecast & $\begin{array}{c}\text { Interval Width } \\
(\mathrm{I})\end{array}$ \\
\hline Constant & $\left(0.1199^{* * *}\right.$ \\
& -0.016 \\
$\mathbb{1}_{\text {Loser }}$ & $(0.021)$ \\
& $0.139^{* *}$ \\
$\mathbb{1}_{D U L+U D W}$ & $(0.024)$ \\
& $0.285^{* * *}$ \\
$\mathbb{1}_{D U W+U D L}$ & $(0.024)$ \\
& Yes \\
\hline Subject Fixed Effects? & 432 \\
$\mathrm{~N}$ & 0.587 \\
Adj. $R^{2}$ & $5.170^{*}$ \\
F Statistic & \\
\hline \hline
\end{tabular}

Table 5 Risk Expectation Regression

This table shows the estimation results of a linear model to explain the width $90 \%$ confidence intervals for the 1-year return forecasts of our participants. $\mathbb{1}_{D U L+U D W}$ indicates the mediumvolatility paths, i.e. Down-Up Loser and Up-Down Winner. $\mathbb{1}_{D U W+U D L}$ indicates the highvolatility paths, i.e. Down-Up Winner and Up-Down Loser.

\section{b) Risk Tolerance and Reference Points}

The location of the reference point is the second aspect that needs to be discussed for better understanding a potential trading decision (Arkes et al., 2008; Benartzi and Thaler, 1995; Barberis et al., 2001; Thaler and Johnson, 1990). We have observed that for a winner and a loser stock with equal past volatility, risk was expected to be equally large in the future for both of them. Assuming risk and return expectations to be equal for the two stocks, the differences in the investment behavior could still stem from differences in risk tolerance, and risk tolerance is sensitive to the location of the reference point, at least given behavioral (classic Prospect Theory) preferences. While outperformance of the reference point is assumed to make investors risk averse, being below the reference point is assumed to turn them risk seeking (Odean, 1999). To understand investment behavior, we hence need to get a reliable insight into the formation of reference points. Traditionally, it has been assumed that the purchase price of a stock is likely to serve as the reference point. However, recent literature has shown that reference points are themselves sensitive to past 
performance (see, for example, Baucells et al. (2011); Gneezy (2005); Heath et al. (1999)).

How do we elicit reference points? We follow Arkes et al. (2008) and assume that a price that exactly equals the reference point will produce zero utility. The reference price is therefore the lowest price that an individual would voluntarily accept in order to sell the stock. We hence asked our participants to state that lowest price for each respective stock. In a further robustness check (see Table 13, Experiment 6), we used the alternative questions "at what price would you feel neutral about selling your stock, i.e., be neither satisfied nor unsatisfied about the sale?") to exclude that the exact wording of our question drives our results. This question also was used by Baucells et al. (2011). Both methods lead to qualitatively the same results on average.

The shifts of the reference points are reported in Table 6 by indicating the difference between the reference point and the current price of each stock. We are interested whether reference points remain at the purchase price or whether they are adapted in the direction of the experienced price movement. We compute unpaired $t$-statistics to find that reference points are shifted more strongly in the direction of the current price after gains than after losses, which is consistent with Arkes et al. (2008) and Jung-Grant et al. (2010). This has one major implication: while under Prospect Theory, static reference points imply that individuals become more risk averse after the experience of gains, this decrease in risk tolerance might be smaller if the reference point is shifted upwards after a gain.

\begin{tabular}{lcccc}
\hline \hline & Down-Up & Straight & Up-Down & All Paths \\
\hline Winner Stocks & $1.94^{*}(1.09)$ & $-1.57(1.26)$ & $-1.31^{*}(0.69)$ & $-0.31(1.87)$ \\
Loser Stocks & $5.36^{* * *}(1.42)$ & $5.36^{* * *}(1.99)$ & $4.71^{* *}(2.10)$ & $5.15^{* * *}(1.04)$ \\
\hline \hline
\end{tabular}

Table 6 Means of the difference between the stated reference price and the current price in percentage points, i.e. ReferencePoint ${ }_{i}-$ CurrentPrice for each of the six price paths. Standard Errors are reported in parentheses. We compute $t$-statistics to test whether the reference point is significantly different from the the current price for each of the six price paths separately.

\section{Behavioral Consequences: Trading Behavior}

We elicited the propensity of holding a stock on a 4-point Likert scale from 1 ("very likely hold") to 4 ("very likely sell") and transformed these values to a scale from 0 to 1 , where 1 indicates the highest propensity to hold. We report the mean propensity to hold for each stock in Table 7 . We observe a relative preference for keeping the stocks with a down-up price path, which seems to be consistent with the subjects' belief in short-term trend continuation as reported in Table 4. We furthermore find that for each pair with the same price path, the loser stock is more likely to be held. Hence, also on the aggregate level, 
a stock is apparently more likely to be held after it has produced losses, which is basically consistent with Prospect Theory and with the literature on the disposition effect (Shefrin and Statman, 1985; Odean, 1999; Grinblatt and Keloharju, 2001). However, interestingly, the stocks with straight price paths show the opposite pattern. We are able to explain this interesting observation with our findings on forecasts earlier in this section, indicating the importance of an approach incorporating beliefs and preferences.

If there are equally many stocks with positive and negative price trend, the "pure" momentum effect is neutralized and the reference point effect, i.e., loss realization aversion, causes loser stocks to be more likely to be held than comparable winner stocks. However, in an environment with overall momentum, it is very likely that individual investors do not like to sell their stocks. This finding has important potential implications on asset pricing theory. In upward moving markets, the updating of reference points is likely to absorb a decrease in risk tolerance as momentum beliefs amplify the upward trend. Odean (1999) argue that the disposition effect is likely to rely on individuals having mean reversion beliefs. Our more detailed analysis of different price paths shows that on the aggregate level, there might be a disposition effect even without participants' having mean-reversion beliefs. However, the example of the straight stock price paths shows that for a rather simplified scenario without significant turning points in past price development, it appears that under trend continuation beliefs, a disposition effect is unlikely to exist. In line with our finding on the reference point dynamics, we can argue that the relatively low willingness to sell winner stocks is partially caused by an upward shift of the reference point. This argument is an alternative to the idea of a house-money account (Thaler and Johnson, 1990; Barberis et al., 2001). The differences in investment behavior for stocks that have produced equal returns is likely to have come from participants' deriving different expectations about future returns from past prices.

\begin{tabular}{lcccc}
\hline \hline & Down-Up & Straight & Up-Down & Non-Straight \\
\hline Winner Stocks & $0.58(0.03)$ & $0.76(0.02)$ & $0.43(0.03)$ & $0.51(0.03)$ \\
Loser Stocks & $0.70(0.03)$ & $0.54(0.03)$ & $0.56(0.03)$ & $0.63(0.03)$ \\
\hline \hline
\end{tabular}

Table 7 Means of the propensity to hold a stock. The original variable is transformed to a scale from 0 to 1 with 1 indicating the highest propensity to hold and 0 indicating the lowest propensity to hold. Standard errors are reported in parentheses.

Is there an effect of satisfaction with the past investment performance with a stock and the propensity to stay invested in that stock? In Table 8, column (I), we present evidence that this effect is indeed positive: The holding propensity increases by 2 percentage points with every additional unit on the satisfaction scale. We observe satisfaction gaps of 1.81 and 2.71 (see Figure 2), which translates into differences in holding propensities of 3.6 and 


\begin{tabular}{|c|c|c|c|c|c|}
\hline \multicolumn{6}{|c|}{ Dependent Variable: Holding Propensity $_{i}$} \\
\hline & (I) & (II) & (III) & (IV) & (V) \\
\hline Constant & $\begin{array}{c}12.210 \\
(19.900)\end{array}$ & $\begin{array}{c}30.401 \\
(19.839)\end{array}$ & $\begin{array}{l}36.368^{*} \\
(19.971)\end{array}$ & $\begin{array}{c}35.730^{* *} \\
(17.771)\end{array}$ & $\begin{array}{c}35.903^{* *} \\
(17.804)\end{array}$ \\
\hline ReturnForecast $_{i}$ & & & & $\begin{array}{c}0.954^{* * *} \\
(0.100)\end{array}$ & $\begin{array}{c}0.939 * * * \\
(0.109)\end{array}$ \\
\hline$\sigma_{\text {Path }}$ & & & $\begin{array}{c}-1.070^{* * *} \\
(0.394)\end{array}$ & $\begin{array}{c}-1.153^{* * *} \\
(0.348)\end{array}$ & $\begin{array}{c}-1.167^{* * *} \\
(0.351)\end{array}$ \\
\hline Price - ReferencePoint ${ }_{i}$ & & & $\begin{array}{c}-0.442^{* *} \\
(0.127)\end{array}$ & & $\begin{array}{l}-0.045 \\
(0.122)\end{array}$ \\
\hline $\mathbb{1}_{\text {Loser }}$ & & $\begin{array}{c}12.269^{* *} \\
(4.892)\end{array}$ & & & \\
\hline $\mathbb{1}_{\text {Loser }} \mathrm{x} \mathbb{1}_{\text {StraightPath }}$ & & $\begin{array}{c}-15.509^{* *} \\
(6.919)\end{array}$ & & & \\
\hline Satisfaction $_{i}$ & $\begin{array}{c}2.003^{* * *} \\
(0.763)\end{array}$ & & & & \\
\hline Subject Fixed Effects? & Yes & Yes & Yes & Yes & Yes \\
\hline $\mathrm{N}$ & 432 & 432 & 432 & 432 & 432 \\
\hline Adj. $R^{2}$ & 0.115 & 0.111 & 0.142 & 0.321 & 0.318 \\
\hline F Statistic & $1.390^{* * *}$ & $1.370^{* *}$ & $1.490^{* * *}$ & $2.400^{* * *}$ & $2.380^{* * *}$ \\
\hline
\end{tabular}

Table 8 Holding Propensity Regression

This Table shows estimation results for several linear models to explain the Holding Propensity of different stocks. Holding Propensity ${ }_{i}$, ReturnForecast $_{i}$ and Price-ReferencePoint ${ }_{i}$ are accounted in percent. $\sigma_{\text {Path }}$ accounts for the annualized standard deviation in percent of the price paths under consideration. Satisfaction ${ }_{i}$ takes values between -4 and 4 .

5.4 percentage points, respectively. As Table 7 shows, stated average holding propensity is different by $15 \%$ and $14 \%$ for down-up and up-down. Hence, satisfaction can account for approximately one fourth and two fifths, for winner and loser stocks respectively, of the variation in the holding propensity for stocks with equal past return.

Column (II) of Table 8 confirms our finding that there is a disposition effect but only for the non-straight stocks. The coefficient for the loser indicator implies that the holding propensity is significantly higher for loser stocks. However, the effect is reversed for the straight price paths: the coefficient for the loser stock with straight path is significantly negative indicating that there is even a reversed disposition effect for stocks with straight price path.

In columns (III)-(V) we test the effect of risk and return expectations as well as shifts 
in reference points. In column (III) we observe that higher volatility decreases the propensity to hold a stock while we also see that for reference points below the current price the holding propensity is increased, thereby implying that for a given current price a lower reference increases the tolerance for risk. In column (IV) we show that a one-percentage point increase in expected return increases the holding propensity roughly by one percentage point. In column $(\mathrm{V})$, however, we see that the effect of the reference point on the holding propensity vanishes once we take into account the return expectations. This is due to the correlation between our participants' reference points and their return expectations $(\rho($ ReferencePoint, ReturnExpectation $)=0.3)$.

\subsection{Two-Observation Extension}

Our experimental setup assumes investors to observe the whole series of past prices at once as this design resembles the real-world situation for many retail investors, who do not consistently monitor their portfolio. However, as some investors might have preferred to sell their stock before the final observation, our results could be biased, and it will be insightful to test our findings in a setting with higher decision flexibility. Hence, in an last control experiment (Experiment 7, Table 12) with 380 MTurkers (38\% female), we split our price series into two parts and allow for an intermediate price observation and a "real" hold/sell decision at that point of time. For each price path, the first observation occurs after seven months, i.e. at the peak/trough of the price series. For the sake of brevity we concentrate on the main results here and present some additional findings in footnotes. Generally, the results of this robustness check fully confirm our previous findings, i.e. these do not rely on the assumption that investors do not observe their portfolio and can take action.

Satisfaction: The satisfaction gaps for those participants who deliberately decided not to sell but to hold their stocks at the first decision are even larger compared to our previous experiments amounting to 3.55 and 3.44 versus 1.81 and 2.71 before (see Table 9). It is particularly noticeable that we find significantly higher average satisfaction level with the overall performance for the down-up loser stock compared with the up-down winner stock. The disappointment of investors who observe their previously well performing stocks to eventually decline in value, seems more pronounced if they had a possibility to sell at a more favorable price. We hypothesize that the possibility to have sold before induces regret. ${ }^{10}$

\footnotetext{
${ }^{10}$ We also asked the participants who sold the stock after the first observation for their satisfaction with their selling decision when they observed the final performance of the stock. We find that dissatisfaction with realized losses (down-up paths) is slightly higher than satisfaction with realized gains (up-down paths). Overall, satisfaction gaps are even larger (in the opposite direction, of course) for those who sold their stocks in the meantime (with a satisfaction gap of 4.33 and 4.12, respectively). The decision to sell seems to induce stronger emotional reactions than staying invested.
} 


\begin{tabular}{|c|c|c|c|c|}
\hline & & $\begin{array}{r}1^{\text {st }} \text { Obs. } \\
\text { All }\end{array}$ & $\begin{array}{l}2^{\text {nd }} \text { Obs. } \\
\text { Holder }\end{array}$ & $\begin{array}{r}2^{\text {nd }} \text { Obs. } \\
\text { Seller }\end{array}$ \\
\hline \multirow{3}{*}{ Winner Stocks } & Down-Up & $-3.71(0.06)$ & $2.43(0.12)$ & $-1.85(0.25)$ \\
\hline & Up-Down & $3.31(0.12)$ & $-1.13(0.17)$ & $2.48(0.21)$ \\
\hline & Satisfaction Gap & & $3.55^{* * *}$ & $4.33^{* * *}$ \\
\hline \multirow{3}{*}{ Loser Stocks } & Down-Up & $-3.61(0.08)$ & $0.34(0.18)$ & $-2.12(0.18)$ \\
\hline & Up-Down & $3.29(0.08)$ & $-3.10(0.11)$ & $2.00(0.32)$ \\
\hline & Satisfaction Gap & & $3.44^{* * *}$ & $4.12^{* * *}$ \\
\hline
\end{tabular}

Table 9 Means of self-reported satisfaction in a two observation setting. Satisfaction is measured on a scale from -4 to +4 . Standard errors are reported in parentheses. Unpaired $t$-statistics are computed to test whether the satisfaction gap is significantly different from zero.

Investment behavior: Also with regard to investment decisions we can confirm our previous findings. At the final (second) observation, we document a classic disposition effect for the now non-straight price paths. Furthermore, we observe that within loser and winner stocks there is a higher propensity to hold stocks with a positive short-term trend (see Table 10). ${ }^{11}$

\begin{tabular}{|c|c|c|c|c|}
\hline & & $\begin{array}{r}1^{\text {st }} \text { Obs. } \\
\text { All }\end{array}$ & $\begin{array}{r}2^{\text {nd }} \text { Obs. } \\
\text { Holder }\end{array}$ & $\begin{array}{r}2^{\text {nd }} \text { Obs. } \\
\text { Seller }\end{array}$ \\
\hline \multirow{2}{*}{ Winner Stocks \{} & Down-Up & $0.65(0.05)$ & $0.49(0.04)$ & $0.33(0.03)$ \\
\hline & Up-Down & $0.72(0.05)$ & $0.46(0.04)$ & $0.28(0.03)$ \\
\hline \multirow{2}{*}{ Loser Stocks \{} & Down-Up & $0.67(0.05)$ & $0.82(0.03)$ & $0.30(0.04)$ \\
\hline & Up-Down & $0.74(0.05)$ & $0.67(0.03)$ & $0.35(0.04)$ \\
\hline
\end{tabular}

Table 10 Propensity to hold, reported in means. On the first observation, selling or holding the stocks is a discrete choice so the value at the first observation indicates the share of participants that decided to hold the stock. On the second observation values are normalized to a scale from 0 to 1 with 1 indicating the highest propensity to hold. (For the Sellers the scale correspondingly represent the propensity to reinvest, i.e. 1 indicates the highest propensity of re-investing into the stock.)

We can also confirm our findings regarding the dynamics of reference points in this more general setting. At the second observation we find the familiar pattern. For prices below the purchase price, i.e. the loser stocks, minimum selling prices for holders remain clearly above

\footnotetext{
${ }^{11}$ At the first observation, all participants observe quasi-straight price paths, and we document again a reversed disposition effect. The share of participants that prefer to hold their stock at the first observation is lower for the down-up paths compared to the up-down paths $(65 \%$ vs. $74 \%$, two-sided $t$-test indicates that values are different at the $5 \%$ level).
} 
the current price while for the winner stocks they almost exactly match the current price. Similarly, we observe on average a belief in short-term momentum. ${ }^{12}$

\section{Discussion and Conclusions}

Despite advances in behavioral finance research, the influence of how investors achieved their returns - the price path that led to the final return - on investor satisfaction and trading decisions, has barely been studied, if at all, and hence it is not well understood. Finance literature mostly focused on simple upward or downward trends or on investor reactions to gains and losses (final returns).

Applying insights from the psychology literature on order preferences to finance, the present study contributes to filling this important gap. We document significant and systematic differences in investors' satisfaction with equal final returns that are caused by the price path with which the final return was achieved. In particular, we find the largest differences between so-called up-down and down-up price paths. As a consequence, investor satisfaction is only partially determined by final returns. In our study, price paths have a substantial effect on investor satisfaction equal to a 13 percentage point return difference. These are important insights which demonstrate that analyzing the influence of past final returns on trading decisions or simple upward and downward trends is insufficient to fully understand and explain investors' behavior.

Additionally to exploring path-dependent satisfaction, our investigation includes the analysis of how price paths affect beliefs (risk and return expectations) as well as preferences (reference points). We present evidence that investors exhibit a strong belief in short-term trend continuation. Hence, price path influence beliefs in the sense that recent trends are extrapolated. These forecasts are an important factor in investment decisions. We further show that for both overall gains and losses, investors use realized volatility for estimating future risk, which suggests that investors are unlikely to become blind to risk, simply because of past gains or losses. Our findings rather demonstrate that a different degree of risk tolerance after overall gains and losses encourages a relative preference for holding loser stocks. Such a change in risk tolerance can be explained by the dynamics of the reference points, which are important determinants of how investors value both financial outcomes as well as risky prospects. While for overall gains, reference points strongly shift in the direction of the current price of a stock, they tend to be more sticky to the purchase price for paper losses, and we hence provide additional robustness to previous findings by Arkes et al. (2008) and Jung-Grant et al. (2010). Our study allows us to conclude that investment decisions are

\footnotetext{
${ }^{12}$ Detailed results are available from the authors upon request.
} 
driven by multiple factors, and the past price path plays an important role that needs to be taken into account.

We see various implications, research possibilities and applications of our work. One example is the disposition effect. We show that this effect is not as universal as might have been assumed. Our findings suggest that the effect can even be reversed for some price paths that enforce investors' momentum beliefs. Future studies should test the robustness of the disposition effect taking into account price paths. Another application is the analysis of previous gains and losses on investor risk-taking which is a topic still debated (Thaler and Johnson, 1990; Zuchel and Weber, 2005; Imas, 2015). While our findings support for a clear distinction between realized and non-realized gains/losses, our results also encourage new research designs for these studies as we provide evidence that it is insufficient to only look at final outcomes. Furthermore, our findings can be tested in the field with actual investor data. Exploring investor behavior for more complex price paths than we used here will potentially offer additional interesting insights. A related research question concerns future purchasing decisions in order to expand on our hold vs. sell approach. Similarly, the evidence that investors are influenced by the sequence of past price developments might not only have an influence on the trading behavior of investors with regard to one particular asset over time. Considering the fact that financial markets as a whole have periods as described by our price paths, it is imaginable that individual investor sentiment has an effect on asset prices in general, hence prices could incorporate a predictable component. We could think about models like the investor sentiment model by Barberis et al. (1998), extended to multiple periods of past prices.

Our study design is also intended to be used by other researchers directly. Stössel and Meier (2015) have already borrowed our idea and controlled for price path dependence in their study on investor risk perception. For different price paths, they document patterns of perceived risk in line with those reported in our study. Nolte and Schneider (2016) recently also analyzed how price path affect investor behavior and use our basic idea and terminology of up-down and down-up price paths in their study. While the authors do not investigate satisfaction they conclude that characteristic price paths shape investor behavior in systematic ways, underlying our contribution in the present paper. 


\section{REFERENCES}

Alexander, J. and Ang, J. S. (1998). Do equity markets respond to earnings paths? Financial Analyst Journal, 54:81-94.

Arkes, H., Hirshleifer, D., Jiang, D., and Lim, S. (2008). Reference point adaption: Tests in the domain of security trading. Organizational Behavior and Human Decision Processes, 105:67-81.

Barberis, N., Huang, M., and Santos, T. (2001). Prospect theory and asset prices. Quarterly Journal of Economics, 116:1-53.

Barberis, N., Shleifer, A., and Vishny, R. (1998). A model of investor sentiment. Journal of Financial Economics, 49(3):307-343.

Baucells, M., Weber, M., and Welfens, F. (2011). Reference point formation and updating. Management Science, 57:506-519.

Benartzi, S. and Thaler, R. (1995). Myopic loss aversion and the equity premium puzzle. The Quarterly Journal of Economics, 110:73-92.

Bergus, G., Gretchen, B., Barcey, T., John, W., and Oppliger, R. (1998). Clinical diagnosis and the order of information. Medical Decision Making, 18:412-417.

Choi, J. J., Laibson, D., and Madrian, B. C. (2010). Why does the law of one price fail? an experiment on index mutual funds. The Review of Financial Studies, 23(4):1405-1432.

Cohn, A., Engelmann, J., Fehr, E., and Marchal, M. (2015). Evidence for countercyclical risk aversion: An experiment with financial professionals. American Economics Review, 105:860-885.

Da, Z., Gurun, U. G., and Warachka, M. (2015). Frog in the pan: Continuous information and momentum. The Review of Financial Studies, 27(7):2171-2218. 
De Bondt, W. (1993). Betting on trends. intuitive forecasts of financial risk and return. International Journal of Forecasting, 9:355-371.

Gaudecker, H.-M.-v. (2015). How does household portfolio diversification vary with financial literacy and financial advice? The Journal of Finance, 70:489-507.

Glaser, M., Langer, T., Reynders, J., and Weber, M. (2007). Framing effects in stock market forecasts: The difference between asking for prices and asking for returns. Review of Finance, 11:325-357.

Gneezy, U. (2005). Updating the reference level: Experimental evidence. Experimental Business Research, pages 263-284.

Goodman, J., Cryder, C., and Cheema, A. (2013). Data collection in a flat world: The strenghts and weakneses of mechanical turk samples. Journal of Behavioral Decision Making, 26:213-224.

Greenwood, R. and Shleifer, A. (2014). Expectations of returns and expected returns. Review of Financial Studies, 27(3):714-746.

Grinblatt, M. and Keloharju, M. (2001). What makes investors trade? The Journal of Finance, 61:589-616.

Grinblatt, M. and Moskowitz, T. J. (2004). Predicting stock price movements from past returns: the role of consistency and tax-loss selling. Journal of Financial Economics, $71(3): 541-579$.

Guyse, J., Keller, L. R., and Eppel, T. (2002). Valuing environmental outcomes: Preferences for constant or improving sequences. Organizational Behavior and Human Decision Processes, 87:253-277.

Haugtvedt, C. and Wegener, D. (1994). Message order effects in persuasion: An attitude strength perspective. Journal of Consumer Research, 21:205-218. 
Heath, C., Larrick, R., and Wu, G. (1999). Goals as reference points. Cognitive Psychology, 38:79-109.

Hendricks, D., Patel, J., and Zeckhauser, R. (1993). Hot hands in mutual funds: Short-run persistence of performance, 1974-1988. The Journal of Finance, 48(1):93-130.

Heyman, J., Mellers, B., Tishcenko, S., and Schwartz, A. (2004). I was pleased a moment ago: How pleasure varies with background and foreground reference points. Motivation and Emotion, 28:65-83.

Hong, H. and Stein, J. (1999). A unified theory of underreaction, momentum trading, and overreaction in asset markets. The Journal of Finance, 54:2143-2169.

Imas, A. (2015). The realization effect: Risk taking after realized versus paper losses. forhtcoming in: American Economic Review.

Ippolito, R. A. (1992). Consumer reaction to measures of poor quality: Evidence from the mutual fund industry. The Journal of Law and Economics, 35(1):45-70.

Jagadeesh, N. and Titman, S. (1993). Returns to buying winners and selling losers: Implications for stock market efficiency. The Journal of Finance, 48:65-91.

Jung-Grant, S., Soman, D., and Xie, Y. (2010). Why do investors update reference prices asymmetrically? Working Paper.

Lawrence, M. and O'Connor, M. (1992). Exploring judgemental forecasting. International Journal of Forecasting, 8:15-26.

Loewenstein, G. and Prelec, D. (1993). Preferences for sequences of outcomes. Psychological Review, 100:91-108.

Merkle, C. (2017). Loss aversion illusion. Working Paper. 
Merkle, C., Egan, D., and Davies, G. (2015). Investor happiness. Journal of Economic Psychology, 49:167-186.

Nolte, S. and Schneider, J. (2016). How price path characteristics shape investment behavior. Working Paper.

Odean, T. (1999). Are investors reluctant to realize their losses? The Journal of Finance, 53:1775-1798.

Read, D. and Powell, M. (2002). Reasons for sequence preferences. Journal of Behavioral Decision Making, 15:433-460.

Rubaltelli, E., Rubichi, S., Savadori, L., Tedeschi, M., and Ferretti, R. (2005). Numerical information format and investment decisions: Implications for the disposition effect and the status quo bias. Journal of Behavioral Finance, 6:19-26.

Shefrin, H. and Statman, M. (1985). The disposition to sell winners too early and ride losers too long: Theory and evidence. Journal of Finance, 40:777-790.

Sirri, E. R. and Tufano, P. (1998). Costly search and mutual fund flows. The Journal of Finance, 53(5):1589-1622.

Stössel, R. and Meier, A. (2015). Framing effects and risk perception: Testing graphical representations of risk for the kiid. Working Paper.

Thaler, R. and Johnson, E. (1990). Gambling with the house money and trying to break even: The effects of prior outcomes on risky choice. Management Science, 36:643-660.

Watkins, B. (2003). Riding the wave of sentiment: An analysis of return consistency as a predictor of future returns. Journal of Behavioral Finance, 4(4):191-200.

Weber, M. and Camerer, C. (1998). The disposition effect in securities trading: an experimental analysis. Journal of Economic Behavior and Organization, 33:167-184. 
Zuchel, H. and Weber, M. (2005). How do prior outcomes affect risk attitudes? Decision Analysis, 2:30-43. 


\section{Appendix A. Experimental Instructions}

Instructions at the beginning of the experiment (Experiments in which participants were presented with multiple charts after each other)

Dear Participant!

In the following you will be presented with four stock price developments. Please imagine for each case that you bought the respective stock a year ago for your own portfolio and you now observe its performance.

The presented performances are not related to the current real world market situation. Furthermore, the performances of all presented stocks are independent of each other.

Please take your time on each stock, imagine this was your own stock which you bought a year ago and ask yourself how you would feel when observing the respective performance. Overall, this study will take you 5-6 minutes.

Instructions at the beginning of the experiment (Experiments with only one stock per participant)

Dear Participant!

In the following you will be presented with one stock price development. Please imagine that you bought the stock one year ago for your own portfolio and you now observe its performance.

The presented performance is not related to the current real world market situation.

Please take your time, imagine this was your own stock which you bought a year ago and ask yourself how you would feel when observing this performance. Overall, this study will take you approx. 2-3 minutes. 


\section{Screenshot of Main Part}
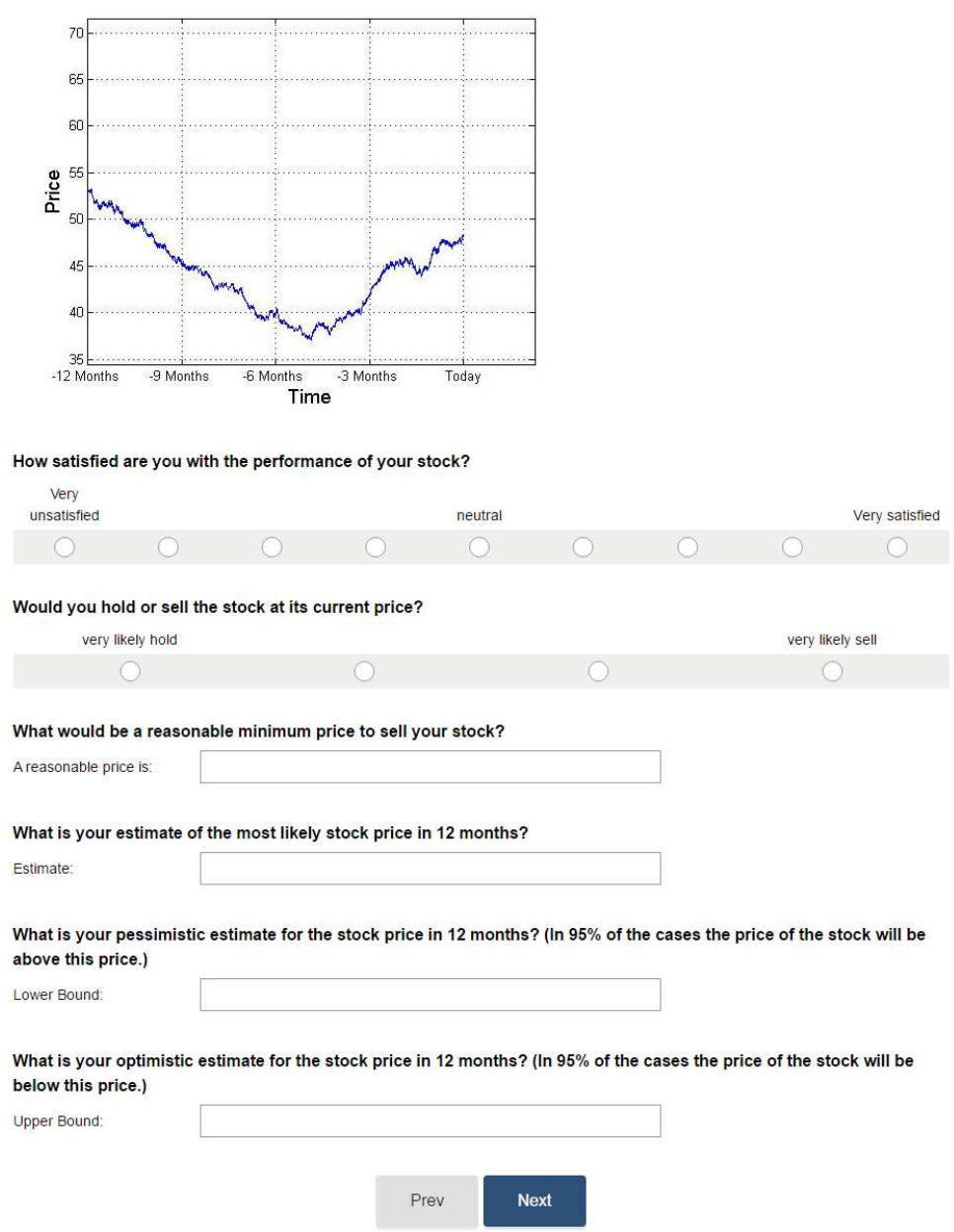

Figure 4. This is a screenshot of the actual experiment which includes the wording of all questions. 


\section{Questionnaire at the end of the experiment}

- How do you assess your knowledge in stock investments compared to the average person? 5-point Likert scale (labels: much worse, average, much better)

- In what mood are you currently? 5-point Likert scale (labels: very bad mood, normal, very good mood)

- Your gender?

- Please enter your age.

- How did you come up with your price forecasts?

- Losses are rather the exception. Stocks are very likely to recover after they have fallen in price.

- If the price chart is downward sloping then prices are probably falling in the future.

- Stocks are very likely to produce positive returns.

- If the current price of a stock is lower than its price one year ago then this stock is very likely to produce further losses.

- If the current price of a stock is higher than its price one year ago then this stock is very likely to produce further gains.

- I don't know.

- If the price chart is upward sloping then prices are probably rising in the future.

- None of the statements applies to me. 


\section{Appendix B. Satisfaction for price paths with less extreme peak and trough prices}
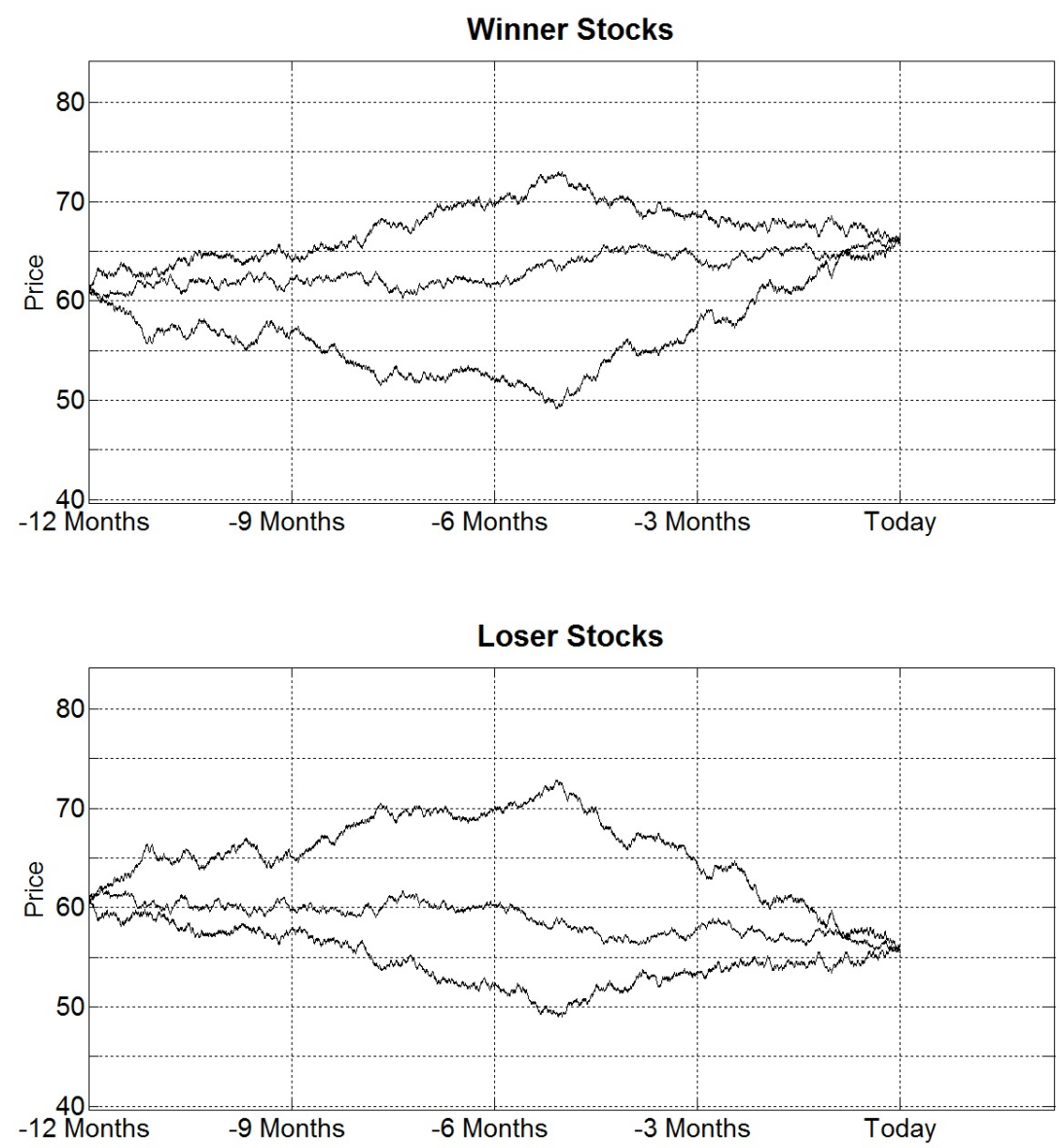

Figure 5. Price paths as used in the student control experiment.

\begin{tabular}{lcccc}
\hline \hline & Down-Up & Straight & Up-Down & satisfaction gap \\
\hline Winner Stocks & $+2.68(0.11)$ & $+1.57(0.15)$ & $+1.05(0.19)$ & $1.63^{* * *}$ \\
Loser Stocks & $-1.12(0.16)$ & $-2.19(0.14)$ & $-2.27(0.13)$ & $1.15^{* * *}$ \\
\hline \hline
\end{tabular}

Table 11 Means of self-reported satisfaction with investment for a sample of 70 advanced finance students, reported on a 9-point Likert scale from -4 to $+4,0$ indicating a neutral evaluation. Price peaks were $10 \%$ lower and troughs were $10 \%$ higher than in the baseline experiments and all participants were presented with the whole set of price paths. Standard errors are reported in parentheses. The satisfaction gap measures the maximum satisfaction difference in one domain (gains or losses). We compute unpaired $t$-statistics to test whether the difference in satisfaction within both domains is different from zero. 


\section{Appendix C. Overview of all experiments}

\begin{tabular}{|c|c|c|c|c|c|}
\hline Exp. & $n$ & $\begin{array}{l}\text { Subject } \\
\text { pool }\end{array}$ & $\begin{array}{l}\text { Stocks } \\
\text { per subject }\end{array}$ & Results reported in & Description of experiment \\
\hline 1 & 144 & Mturk & 3 & $\begin{array}{l}\text { Figure } 2 \\
\text { Tables } 1,4,5,6,7,8\end{array}$ & Baseline experiment with forecast interval question \\
\hline 3 & 70 & $\begin{array}{l}\text { Finance } \\
\text { students }\end{array}$ & $3+3$ & Table 11 & Less pronounced peaks/troughs \\
\hline 5 & 500 & Mturk & 1 & Table 14 & Different timing of turning points \\
\hline 6 & 564 & Mturk & 1 & Section $3.3 .2 \mathrm{e})$ & $\begin{array}{l}\text { Asking subjects about realism of paths } \\
\text { Using different question to elicit reference points }\end{array}$ \\
\hline 7 & 380 & Mturk & 1 & Tables 9,10 & $\begin{array}{l}\text { Two-observation extension: } \\
\text { Subjects with possibility to sell in before end }\end{array}$ \\
\hline
\end{tabular}

Table 12 Overview of all experiments discussed in this paper. Number of participants $n$ is after exclusion of subjects that completed the survey in less than a pre-specified time. 


\section{Appendix D. Statistical Characteristics of the Return Series}

\begin{tabular}{rrrrrrr}
\hline \hline \multirow{6}{*}{ Winner } & & $\sigma^{\text {daily }}$ & $\sigma^{\text {annual }}$ & Skewness & Kurtosis \\
\hline \multirow{6}{*}{ up-down } & Normal & 0.009 & 0.164 & 0.069 & 2.692 \\
& & Early & 0.012 & 0.226 & 0.350 & 4.009 \\
& & Late & 0.012 & 0.238 & -0.103 & 3.616 \\
\cline { 3 - 7 } & down-up & Normal & 0.009 & 0.170 & 0.005 & 2.855 \\
& & Early & 0.008 & 0.162 & -0.732 & 4.829 \\
& & Late & 0.010 & 0.184 & 0.636 & 4.530 \\
\cline { 3 - 7 } Loser & \multirow{4}{*}{ up-down } & Normal & 0.009 & 0.170 & -0.005 & 2.855 \\
& & Early & 0.008 & 0.162 & 0.732 & 4.829 \\
& & Late & 0.010 & 0.184 & -0.636 & 4.530 \\
\cline { 3 - 7 } & down-up & Normal & 0.009 & 0.164 & -0.069 & 2.692 \\
& & Early & 0.012 & 0.226 & -0.350 & 4.009 \\
& & Late & 0.012 & 0.238 & 0.103 & 3.616 \\
\hline \hline
\end{tabular}

Table 13 Statistical Properties of the return series of all price paths. Returns are aggregated in blocks of 10 , meaning that from 2520 tick changes we obtain 252 aggregated returns of which we report properties here.

\begin{tabular}{|c|c|c|c|c|}
\hline & & Early & Late & Difference \\
\hline \multirow{2}{*}{ Winner Stocks } & down-up & $1.74(0.19)$ & $1.22(0.22)$ & $0.52^{* *}$ \\
\hline & up-down & $0.08(0.18)$ & $0.41(0.20)$ & -0.33 \\
\hline \multirow{2}{*}{ Loser Stocks } & down-up & $-0.97(0.22)$ & $-1.59(0.20)$ & $0.62^{* * *}$ \\
\hline & up-down & $-2.87(0.12)$ & $-2.69(0.19)$ & -0.18 \\
\hline
\end{tabular}

Table 14 This table compares the stated satisfaction for early and late turning points. Satisfaction is measured on a scale from -4 to +4 . We compute t-statistics to test whether the unpaired differences in satisfaction between early and late turning point are significantly different from zero. 